\title{
Frequency Dependence of Electrical Response of Polycrystalline LCMO Thin Films
}

\author{
S. Ašmontas ${ }^{a, c, *}$, F. Anisimovas ${ }^{a}$, S. BalevičIUs $^{a}$, \\ P. Cimmperman ${ }^{a}$, J. Gradauskas ${ }^{a, b}$, A. LuČun ${ }^{a}$, \\ V. StankeViČ ${ }^{a}$, A. SuŽIEdĖlis ${ }^{a, b}$, B. Vengalis ${ }^{a, b}$ \\ AND N. ŽURAUSKIENE $\dot{E}^{a}$ \\ ${ }^{a}$ Semiconductor Physics Institute, A. Goštauto 11, 01108 Vilnius, Lithuania \\ ${ }^{b}$ Vilnius Gediminas Technical University \\ Saulètekio al. 11, 2040 Vilnius, Lithuania \\ ${ }^{c}$ KTU Panevėžys Institute, Klaipėdos 3, 5319 Panevėžys, Lithuania \\ Influence of strong electric field in wide frequency range (from DC to \\ $35 \mathrm{GHz}$ ) on electrical resistance of thin $\mathrm{La}_{0.67} \mathrm{Ca}_{0.33} \mathrm{MnO}_{3}$ polycrystalline \\ manganite films was investigated in the range of $(78 \div 300) \mathrm{K}$. Different be- \\ havior of resistance change vs. temperature was observed when pulsed DC \\ electric field and microwaves were applied to the films. When pulsed DC \\ electric field is applied the electric-field-induced resistance change ("elec- \\ troresistance") of manganite film depended nearly monotonically on tem- \\ perature. However, in microwave electric fields a non-monotonic character \\ of the electroresistance temperature dependence was observed. The depen- \\ dence of the electroresistance on quality of manganite films was observed \\ in case of microwaves. The experimental findings are explained assuming \\ different electrical current mechanisms in case of DC and microwave fields. \\ The applied voltage drops mainly across the grains of polycrystalline film \\ due to a presence of displacement currents in case of microwaves, whereas in \\ $\mathrm{DC}$ case the voltage drop is across the grain boundaries.
}

PACS numbers: 75.47.Gk, 75.47.Lx, 07.57.Kp

\section{Introduction}

Increased interest in rare-earth manganese perovskites is conditioned by promising application possibilities of their "colossal" magnetoresistance (CMR) and spin-polarized carriers in new magnetic devices and sensors. However, both

*corresponding author; e-mail: as@uj.pfi.lt 
electrical and magnetic properties of the materials are still under investigation by many scientific groups around the world. Recently, microwave radiation was used in the investigation of the manganite films having various crystalline quality [1]. Results of these investigations confirm phase separation concept in the manganites and prove a dominant role of grain boundaries in high frequency transport in polycrystalline films. Recent electrical transport investigations in the manganite films using short electrical pulses revealed the influence of pulsed strong electric field on electrical resistivity [2]. However, the nature of the strong electric-field-induced resistance change of the manganite films electroresistance (ER) $[3-5]$ is not clarified properly yet.

In this paper we present the results of experimental investigations of the "electroresistance" of $\mathrm{La}_{0.67} \mathrm{Ca}_{0.33} \mathrm{MnO}_{3}$ films prepared under different conditions in strong pulsed and microwave $(\mathrm{MW})$ electric fields in $(78 \div 300) \mathrm{K}$ temperature range.

\section{Samples and experimental procedure}

The polycrystalline $\mathrm{La}_{0.7} \mathrm{Ca}_{0.3} \mathrm{MnO}_{3}$ (LCMO) films with the thickness $d=$ $(100 \div 400) \mathrm{nm}$ were grown in situ at $750^{\circ} \mathrm{C}$ on lucalox substrates by on-axis pulsed laser deposition using $\mathrm{Nd}^{3+}$ :YAG laser operating in a single mode $(\lambda=1064 \mathrm{~nm})$ regime. Laser pulse energy was chosen to be $50 \mathrm{~mJ}$. During the deposition, the temperature of the substrate was kept at $750^{\circ} \mathrm{C}$. After the deposition films were annealed at $750^{\circ} \mathrm{C}$ for $30 \mathrm{~min}$ in oxygen ambient of $1 \mathrm{~atm}$ pressure followed by slow cooling (for 3 hours) of the samples down to room temperature. The stripe-like LCMO layers with thermally evaporated $\mathrm{Ag}$ contact pads at $200^{\circ} \mathrm{C}$ were fabricated. After annealing the $\mathrm{Ag}$ contacts for $20 \mathrm{~min}$ at $1 \mathrm{~atm}$ pressure in argon gas at $400^{\circ} \mathrm{C}$ the samples were ready for investigations.

Samples were investigated in DC pulsed and microwave electric fields. The pulsed field was rectangular with 0.5 ns rise time and 5-10 ns duration. The microwave electric fields of frequency 10 and $35 \mathrm{GHz}$ had a pulse duration $2 \mu \mathrm{s}$ and repetition rate of $40 \mathrm{~Hz}$. The maximal power of microwave was $8 \mathrm{~kW}$ and $0.8 \mathrm{~kW}$, respectively. The samples were placed into the center of a rectangular waveguide perpendicular to the wide waveguide walls. Resistance change in microwaves was measured applying low DC bias voltage to the sample.

\section{Results and discussion}

Temperature dependence of electrical resistance of the sample of polycrystalline LCMO manganite film of $140 \mathrm{~nm}$ thickness and the gap between contacts $130 \mu \mathrm{m}$, was measured in low electrical field regime and is presented in Fig. 1. The sample resistance increases at temperatures above $T_{\mathrm{m}}=120 \mathrm{~K}$ and the decrease below $T_{\mathrm{m}}$ was observed with sample cooling. This is typical of manganites. The resistance derivative versus temperature is depicted in Fig. 1, too. The temperature dependence of the derivative should trace the dependence of microwave 


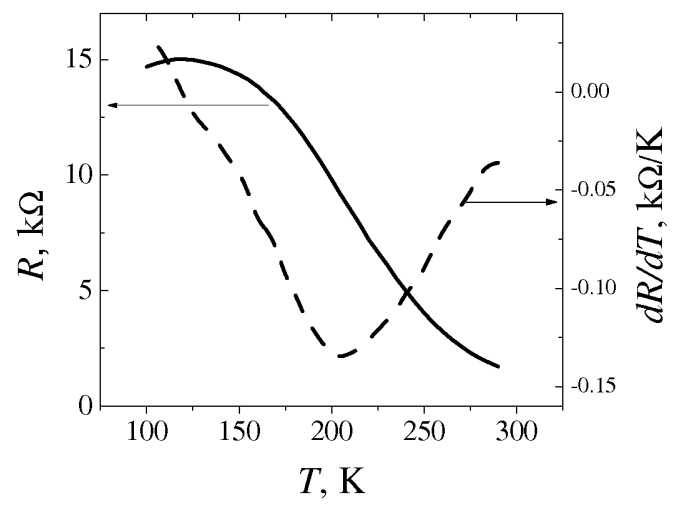

Fig. 1. Resistance versus temperature (solid line) and the temperature derivative dependence on temperature (dashed line) for the polycrystalline $\mathrm{La}_{0.67} \mathrm{Ca}_{0.33} \mathrm{MnO}_{3} /$ lucalox thin film.

and pulsed electric-field-induced resistance response on temperature in case the response has a bolometric nature.

The electric-field-induced resistance response of the investigated manganite films reflects the "electroresistance" $\mathrm{ER}=[R(E)-R(0)] / R(0)$, where $R(E)$ is the resistivity at certain electric field strength $E$ and $R(0)$ stands for the film resistance at zero field. Figure 2a depicts temperature dependence of the electroresistance of the thin LCMO film of $140 \mathrm{~nm}$ thickness that was exposed to impact of the microwaves and pulsed strong electric fields. There should be noticed the different values of the ER for microwaves and pulsed electric field: the pulsed electric field changes the electrical resistance of the manganite film more effectively than MW radiation. The temperature dependences of the ER are also different for MW and strong pulsed electric field cases. In temperatures above $T_{\mathrm{m}}=200 \mathrm{~K}$ the ER follows the dependence of the $\mathrm{d} R / \mathrm{d} T$ vs. $T$. Below $T_{\mathrm{m}}$ ER starts to decrease at exposing of film to the microwave radiation. In pulsed electric fields the ER increases with temperature decrease. These experimental findings can be explained assuming different electrical current transport mechanisms in pulsed and microwave electric fields. Certainly, due to shunting intergrain capacitance the MW voltage drops mainly across the grains of polycrystalline film due to a dominant character of displacement current of the microwaves, whereas the pulsed electric field drop is prevailing across the grain boundaries. The frequency dependence of the microwave-induced resistance change may be understood taking into account that the microwave radiation of $35 \mathrm{GHz}$ frequency would cause greater resistance change at temperatures above the transition temperature $T_{\mathrm{m}}$, while below the transition temperature greater resistance change might be induced at $10 \mathrm{GHz}$.

Figure $2 \mathrm{~b}$ presents ER dependences on temperature for the LCMO film of better crystalline quality exposed to the influence of MW radiation at $f=35 \mathrm{GHz}$ 

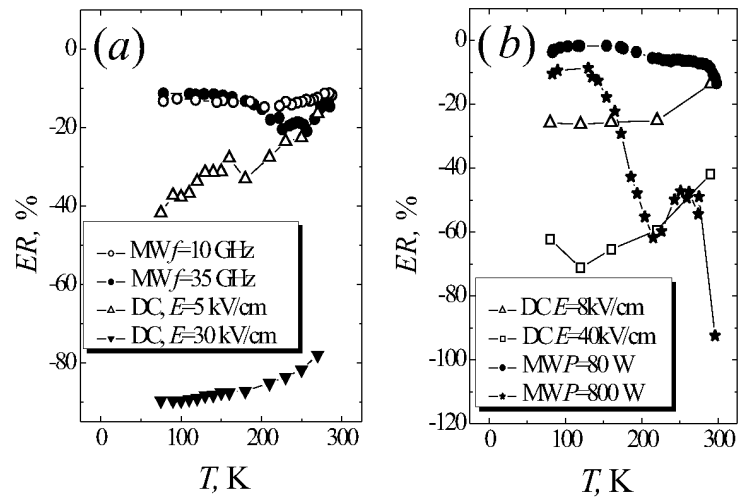

Fig. 2. Temperature dependence of electroresistance of the $140 \mathrm{~nm}$ (a) and $400 \mathrm{~nm}$ (b) LCMO manganite film under the influence of MW and pulsed strong electric field.

and by applying the pulsed electric field. A more evident difference in the temperature dependence of the ER on MW and pulsed electric field is seen here. Sharp decrease in the absolute value of the electroresistance exposed to the strong microwave radiation below transition temperature points out the dominance of resistance change in the grains of the manganite film when it is irradiated by high frequency microwaves. Higher value of the ER under MW radiation in comparison with that for $140 \mathrm{~nm}$ LCMO film can be explained by better match of waveguide impedance with sample resistance as well as better quality of thicker manganite film $(400 \mathrm{~nm})$ and shorter gap between contacts $(\approx 50 \mu \mathrm{m})$. In the case of the pulsed electric field the temperature dependence of the ER is monotonic in whole temperature range exhibiting dominant influence of the grain boundaries of manganite film to electroresistance. The pulsed voltage drop across the grain boundaries determines further resistance decrease below transition temperature due to the tunneling effects in manganite film.

\section{Conclusions}

Experiments of the interaction of polycrystalline LCMO manganite films with strong microwave and pulsed electric fields allows us to conclude:

- in a case of MW field, the applied voltage drops mainly across the grains of polycrystalline film due to a dominant character of displacement current of the microwaves, whereas the pulsed electric field drops across grain boundaries;

- the difference of electroresistance of the polycrystalline manganite films in case of MW and pulsed electric field is more pronounced for thicker films of better crystalline quality due to better absorption of microwave radiation by manganite film. 


\section{Acknowledgments}

This work was partially supported by the EC within Centres of Excellence project PRAMA.

\section{References}

[1] S. Ašmontas, A. Abrutis, J. Gradauskas, A. Lučun, A. Oginskis, V. Plaušinaitienè, A. Sužiedèlis, B. Vengalis, Acta Phys. Pol. A 105, 141 (2004).

[2] P. Cimmperman, V. Stankevič, N. Žurauskienè, S. Balevičius, F. Anisimovas, J. Paršeliūnas, O. Kiprijanovič, L.L. Altgilbers, Acta Phys. Pol. A 105, 107 (2004).

[3] A. Asamitsu, Y. Tomioka, H. Kuwahara, Y. Tokura, Nature 388, 50 (1997).

[4] S.B. Ogale, V. Talyansky, C.H. Chen, R. Ramesh, R.L. Greene, T. Venkatesan, Phys. Rev. Lett. 77, 1159 (1996).

[5] N.I. Solin, A.A. Samochvalov, S.V. Naumov, Fiz. Tverd. Tel. 40, 1881 (1998). 